\title{
Part 5: Postscript
}

\section{Future directions and challenges for system dynamics}

\section{G Richardson}

In January 1998 a meeting of the UK system dynamics community took place in Alton, Hampshire, hosted by HVR Consulting. The meeting provided an opportunity to gather many of the authors contributing to this volume and to share with them plans for the collection. In preparation for the meeting all participants were asked to read George Richardson's paper 'Problems for the Future of System Dynamics' (System Dynamics Review, 12: 141-157, Summer 1996). A series of talks on the day addressed the themes raised in the paper, and George himself was a guest speaker at the event.

Appropriately therefore, the postscript to the special issue is an invited paper from George Richardson. The paper revisits his future problems and challenges, building on ideas from the Alton 98 meeting, the JORS manuscript collection and the author's own in-depth professional knowledge of the field. We (the editors) also invited him to write a special supplementary piece describing preuniversity (K-12) education in system dynamics. Earlyyears education in feedback systems thinking is gaining momentum in the United States, but so far little has happened in Europe (with the exception of pilot projects in Scandinavia). We felt that a special issue of JORS dedicated to system dynamics should include K-12 educational initiatives. The initiatives are interesting and they will help shape the field's future.

George Richardson is a Professor of Public Policy at the State University of New York (SUNY) at Albany. He is an acknowledged leader of the field, and one of its most productive and frequently cited authors.

Geoff Coyle and John Morecroft 